\title{
Comparison of recognition about denture adhesive between Japanese and Indonesian dentists: A pilot study
}

\author{
Shinsuke Sadamori, ${ }^{*}$ Taizo Hamada, ${ }^{*}$ Guang Hong, ${ }^{*}$ Nakai Nakai, ${ }^{*}$ Makoto Kawamura, and Arifzan Razak ${ }^{* * *}$ \\ *Department of Prosthetic Dentistry, Graduate School of Biomedical Sciences, Hiroshima University, Hiroshima, Japan \\ ** Department of Prosthodontics, The Faculty of Dentistry, Airlangga University, Surabaya, Indonesia
}

\begin{abstract}
The purpose of this study was to compare cross-national differences of the recognition of denture adhesive among dentists. The design of the research was cross-cultural differences. The research was done in Japan and Indonesia. One hundred and ten dentists from Japan and Indonesia were surveyed using a questionnaire regarding knowledge/comprehension of denture adhesive (in Japanese and Indonesian versions respectively). Logistic regression model (forward stepwise method) showed that it was possible to distinguish Japanese dentists from Indonesian peers with a probability of 96.0 per cent by using 4 items out of 16. For the question of "How many domestic products of denture adhesive (DA) do you know?" approximately a half of the Japanese dentists answered "less than 3", whereas 93 per cent of Indonesian subjects answered "nothing". It was concluded that there were much differences in dentists' understanding and experience of denture adhesive in the clinic, between Japan and Indonesia.
\end{abstract}

Key words: denture adhesive, cross-national differences, dentists, Japan, Indonesia

Correspondence: Dr Shinsuke Sadamori, Department of Prosthetic Dentistry, Graduate School of Biomedical Sciences, Hiroshima University, 1-2-3 Kasumi, Minami-ku, Hiroshima, 734-8553, Japan, Tel: +81-82-257-5681, FAX: +81-82-257-5684, E-mail: tsada@hiroshima-u.ac.jp

\section{INTRODUCTION}

Denture adhesive has been used by denture wearers as a means to enhance denture retention, stability, and function. ${ }^{1-6}$ In the clinic, a negative opinion toward denture adhesive has existed, ${ }^{7-10}$ and dentists have been slow to accept it in their clinic. The first patent for denture adhesive was issued in 1913 in the US, with other patents following in the 1920s and 1930s. ${ }^{11}$ However, the American Dental Association first reported the use of denture adhesive in 1935. ${ }^{12}$ Denture adhesive was imported into Japan in 1951. After that, many Japanese original denture adhesives were selling on the market in the 1970s and 1980s. ${ }^{13}$

Several reports noted that the main reasons for the use of denture adhesive are to improve fit, comfort, chewing ability, and also to improve patient confidence in wearing dentures. ${ }^{5,14}$ Fifteen per cent of denture wearers in the US used denture adhesives in 1980. ${ }^{15,16}$ Wilson et al. ${ }^{17}$ reported that 30 per cent of denture wearers used, or had used, denture adhesive. However Coates ${ }^{18}$ reported that a significant number of subjects in his study did not know that denture adhesives existed. Denture adhesives at present would have a legitimate and indispensable place in prosthetic dental treatment.

Testing method, mechanical properties, and cytotoxicity of denture adhesives have been widely investigated. ${ }^{19-23}$ Although the knowledge level of denture wearers about denture adhesive has been investigated, 14,18,24 knowledge/ experience about denture adhesive among dentists has not been clarified. If Japanese dentists could be distinguished from Indonesian peers only by using the questionnaire, it could indicate a difference between the degree of knowledge and interest of dentists regarding denture adhesive use. The synthetic recognition about denture adhesive by dentists seems to, in future, motivate their patients and affect its use in the clinic. Therefore, the purpose of this study was to clarify dentists' recognition about denture adhesive and to examine cross-national differences in dentists' recognition.

\section{MATERIALS AND METHODS}

In this study, 110 subjects were surveyed to complete and return a structured questionnaire (see Table 1). The subjects in this pilot study were selected from dentists in Japan (Hiroshima University, Hiroshima) and Indonesia (Airlangga University, Surabaya). They included 43 dentists (men: 27, women: 16) at Hiroshima University and 65 dentists at Airlangga University. (men: 30, women: 35) Mean age of the Japanese dentists was not statistically significant compared to that of Indonesian peers (30.1 and 38.6 years respectively). In the survey, the distribution and collection of the questionnaire was instituted by the staff of this survey in Hiroshima and Airlangga University in 2002. This questionnaire was administered after explanation was given to all subjects about the aim of this survey, and understanding and consent from all subjects was gained. 
The questionnaire was produced in Japanese and then translated into English. Then, it was discussed with the staff in Indonesia, and this survey was instituted by the same estimation criterion. The answers were evaluated in three steps of "No" or "Nothing" (score 0), "Yes, but a little" or "Occasionally" (score 1) and "Yes, very much" or "Often" (score 2).

Chi-square tests were used to examine the difference of responses for each item on the questionnaire between the two countries. Then, two stepwise logistic regression analyses were carried out on the dependent variable (country). The Wald statistic was used to test the null hypothesis that the regression coefficients were zero. The Negelkerke $\mathrm{R}^{2}$ statistic was used to discriminate how well the model is able to distinguish between the interest and knowledge of dentists in the two countries. All analyses were computed using SPSS for Windows operating system (SPSS 10, SPSS Japan Inc., Tokyo, Japan).

\section{RESULTS}

The recovery rate was 99.1 per cent. The recovery rate of the subjects at Hiroshima University was 100 per cent, and that of Airlangga University was 98.5 per cent.

Table 1 presents questionnaire items and percentage distribution of responses. Significant differences between the two countries were found for 12 questions. For the question of "How many domestic products of denture adhesive (DA) do you know?" about a half of the Japanese dentists answered "less than 3", whereas 93 per cent of subjects in Indonesia answered "nothing".

Table 1. Questionnaire items and percentage distribution of the answers by country

\begin{tabular}{|c|c|c|c|c|c|c|c|}
\hline \multirow{2}{*}{\multicolumn{3}{|c|}{ Item descriptions }} & \multicolumn{3}{|c|}{ category score } & & \multirow{2}{*}{$\chi^{2}$ test } \\
\hline & & & \multirow{2}{*}{$\frac{2}{42}$} & \multirow{2}{*}{$\frac{1}{56}$} & \multirow{2}{*}{$\begin{array}{l}0 \\
2\end{array}$} & & \\
\hline Q 1. & Do you know the denture adhesive? & JPN & & & & A & NS \\
\hline & & INA & 31 & 66 & 3 & & \\
\hline \multirow[t]{2}{*}{ Q 2.} & Do you know any purposes of the denture adhesive? & JPN & 42 & 58 & 0 & A & NS \\
\hline & & INA & 32 & 65 & 3 & & \\
\hline \multirow[t]{2}{*}{ Q 3.} & Do you know any disadvantages of the denture adhesive? & JPN & 33 & 53 & 14 & A & $* *$ \\
\hline & & INA & 16 & 44 & 40 & & \\
\hline \multirow[t]{2}{*}{ Q 4.} & How many imported products of denture adhesive do you know? & JPN & 14 & 26 & 60 & B & $* * *$ \\
\hline & & INA & 10 & 62 & 28 & & \\
\hline \multirow[t]{2}{*}{ Q 5.} & How many domestic products of denture adhesive do you know? & JPN & 35 & 51 & 14 & B & $* * *$ \\
\hline & & INA & 0 & 7 & 93 & & \\
\hline \multirow[t]{2}{*}{ Q 6.} & Have you ever been taught about the denture adhesive? & JPN & 21 & 58 & 21 & C & $* * *$ \\
\hline & & INA & 0 & 52 & 48 & & \\
\hline \multirow[t]{2}{*}{ Q 7.} & Have you ever taught the denture adhesive to your students? & JPN & 5 & 14 & 81 & $\mathrm{C}$ & NS \\
\hline & & INA & 3 & 25 & 72 & & \\
\hline \multirow[t]{2}{*}{ Q 8. } & Have you ever seen the denture adhesive in books or lecture meetings? & JPN & 28 & 58 & 14 & $\mathrm{C}$ & $*$ \\
\hline & & INA & 8 & 70 & 22 & & \\
\hline \multirow[t]{2}{*}{ Q 9.} & Have you ever seen any TV commercials about the denture adhesive? & JPN & 37 & 56 & 7 & $\mathrm{C}$ & $* * *$ \\
\hline & & INA & 2 & 3 & 95 & & \\
\hline \multirow[t]{2}{*}{ Q10. } & Do you know any goods instead of the denture adhesive? & JPN & 16 & 42 & 42 & A & $*$ \\
\hline & & INA & 2 & 44 & 54 & & \\
\hline \multirow[t]{2}{*}{ Q11. } & Have you ever applied the denture adhesive to patients? & JPN & 2 & 26 & 72 & $\mathrm{C}$ & $* *$ \\
\hline & & INA & 5 & 55 & 40 & & \\
\hline \multirow[t]{2}{*}{ Q12. } & Have you ever seen the denture adhesive in the clinic? & JPN & 14 & 49 & 37 & C & $*$ \\
\hline & & INA & 19 & 65 & 16 & & \\
\hline \multirow[t]{2}{*}{ Q13. } & Have you ever let your patients use the denture adhesive? & JPN & 7 & 28 & 65 & $\mathrm{C}$ & $* *$ \\
\hline & & INA & 9 & 61 & 30 & & \\
\hline \multirow[t]{2}{*}{ Q14. } & Have you ever applied the denture adhesive for stability of the base & JPN & 5 & 30 & 65 & $\mathrm{C}$ & $* * *$ \\
\hline & plate in the clinic? & INA & 3 & 66 & 31 & & \\
\hline \multirow[t]{2}{*}{ Q15. } & Do you think the use of denture adhesive is more & JPN & 5 & 67 & 28 & A & NS \\
\hline & effective than medical intervention such as relining? & INA & 2 & 58 & 40 & & \\
\hline \multirow[t]{2}{*}{ Q16. } & Do you think the price of denture adhesives is reasonable? & JPN & 5 & 65 & 30 & A & $*$ \\
\hline & & INA & 5 & 39 & 56 & & \\
\hline
\end{tabular}
A 2: Yes, very much,
1: Yes, but a little,
$0:$ No
B 2: Three and more,
1: Less than three,
0 : Nothing
C 2: Yes, often,
1: Yes, occasionally, 0: No 
Table 2 shows the estimated coefficient and related statistics from the logistic regression model that predicts group membership. The model contained four variables by forward stepwise method $(\mathrm{P}<0.01)$ : Q14 (Application of DA for stability), Q9 (TV commercial about DA), Q5 (Number of domestic DA) and Q2 (Understanding of purposes of the use of DA). The model contained six variables by backward stepwise method $(\mathrm{P}<0.05)$ : Q1 (Understanding of DA), Q3 (Understanding of disadvantage of DA), Q5 (Number of domestic DA), Q9 (TV commercial about DA), Q12 (Utilization of DA in the clinic) and Q14 (Application of DA for stability).

Table 2. Results of binary logistic regression analysis using 2 Wald methods

\begin{tabular}{|c|c|c|c|c|c|c|}
\hline Item No. & $\mathrm{B}$ & S.E. & Wald chi-square & Freedom & $\mathrm{P}$ & $\operatorname{Exp}(B)$ \\
\hline \multicolumn{7}{|l|}{ Forward Stepwise (Wald) } \\
\hline Q14: Application of DA* for stability & 3,43 & 1,20 & 8,11 & 1 & 0,004 & 30,90 \\
\hline Q 9: TV commercials about $\mathrm{DA}^{*}$ & $-2,64$ & 0,80 & 10,86 & 1 & 0,001 & 0,07 \\
\hline Q 5: Number of domestic DA * & $-4,02$ & 1,35 & 8,90 & 1 & 0,003 & 0,02 \\
\hline Q 2: Understanding of purposes of the use of DA* & 2,35 & 0,78 & 9,12 & 1 & 0,003 & 10,51 \\
\hline \multicolumn{7}{|l|}{ Backward Stepwise (Wald) } \\
\hline Q 5: Number of domestic DA * & $-4,60$ & 1,57 & 8,59 & 1 & 0,003 & 0,01 \\
\hline Q12: Utilization of DA* in the clinic & 2,46 & 1,08 & 5,21 & 1 & 0,022 & 11,76 \\
\hline Q14: Application of DA* for stability & 2,81 & 1,24 & 5,16 & 1 & 0,023 & 16,57 \\
\hline Q 9: TV commercials about $\mathrm{DA}^{*}$ & $-1,67$ & 0,77 & 4,75 & 1 & 0,029 & 0,19 \\
\hline Q 1: Understanding of $\mathrm{DA}^{*}$ & 2,32 & 1,08 & 4,65 & 1 & 0,031 & 10,22 \\
\hline Q 3: Understanding of disadvantage of DA* & $-2,14$ & 1,08 & 3,91 & 1 & 0,048 & 0,12 \\
\hline
\end{tabular}

* denture adhesive

- For forward stepwise, variables were entered in steps 1 to $4 \bullet$ Q14, Q9, Q5, Q2 in that order.

- For backward stepwise, variables were removed in steps 1 to $11 \bullet$ Q11, Q8, Q13, Q7, Q16, Q2, Q4, Q6, Q10, Q15 in that order.

Table 3 presents that 41 Japanese dentists (95.3 per cent) were correctly predicted by the former model. Similarly, 56 Indonesian dentists ( 96.6 per cent) were correctly predicted. The Nagelkerke $\mathrm{R}^{2}$ statistic was 0.853 ; that is, 85.3 per cent of the variation in the outcome variable was explained by the logistic regression model.

Table 3. Observed and predicted group membership using 2 Wald methods

\begin{tabular}{lccc}
\hline \multicolumn{1}{c}{ Country } & \multicolumn{2}{c}{ Predicted country } & $\begin{array}{c}\text { Percentage } \\
\text { correct }\end{array}$ \\
\cline { 2 - 3 } & Japan & Indonesia & \\
\hline Forward Stepwise (Wald) & & & 95,3 \\
$\quad$ Japan & 41 & 2 & 96,6 \\
$\quad$ Indonesia* & 2 & 56 & 96,0 \\
$\quad$ Total & & & \\
Backward Stepwise (Wald) & 41 & 2 & 95,3 \\
$\quad$ Japan & 3 & 55 & 94,8 \\
$\quad$ Indonesia & & & 95,0 \\
$\quad$ Total & & & \\
\hline
\end{tabular}

The cut value is 0.50 .

Negalkerke R2 = 0.853 (forward stepwise), 0.878 (backward stepwise).

* Seven dentists were delated because they did not give complete answers in the questionnaire.

\section{DISCUSSION}

There are various differences in the environment between the two countries. These differences could affect dental treatment, and affect the use of denture adhesive.

From the answers of Q1 (Understanding of DA) and Q3 (Understanding of disadvantage of DA), there was a difference in understanding about denture adhesive between Japanese and Indonesian dentists. There was a difference in the answers for Q9 (TV commercials about DA) "Have you ever seen any TV commercials about denture adhesive?". These results are likely caused by differences in the popularity of mass media, commercials on television, and so on. The number of televisions per 1000 people in Japan was 613 and that in Indonesia was 59 in 1999.25 There seems to be a difference between countries as to the quantity of information from television. No difference between countries was seen in response to Q6 (Receiving instruction about DA) or Q7 (Instruction about DA to students). There would be little, or no difference in school education of both countries concerning denture adhesive. The results support the same opinion reported by Ozan et al, ${ }^{14}$ which should be taught more intensively at dental schools.

The basic concept of the diffusion of innovation model proposed by Rogers and Shoemaker ${ }^{26}$ is how different 
people pass through the five stages: awareness, interest, trial, decision, and adoption. They described five groups of adopters: innovators, early adopters, early majority, late majority, and laggards. Those who adopt an innovation earliest, the innovators, tend to be middleclass people who are more adventurous and actively seek information about new ideas. In the first three groups, people adopt a change primarily on the basis of their reasoning about costs, and benefits of an innovation. TV commercials about denture adhesive may have an effect on awareness and interest of those with dentures. The adoption of an idea, like the adoption of any product, requires a deep understanding of people's needs and perceptions, preferences of the reference groups, and behavioral patterns of the target audience. The late majority is lower in social influence and social status, and learns of new ideas primarily from peers through social influence, rather than from media channels. All people are probably receivers of the message, but only the most influential and well informed have special qualifications about how the message should be understood and assessed. Further knowledge needed about the tailoring of messages, the effect of media, 'costs', and facilities to maximize the case for adopting the idea.

The percentage of answers for Q5 (Number of domestic DA) is very different in Japan than in Indonesia. For the answer "Nothing" is 14 per cent in Japan, compared to 93 per cent in Indonesia. The problem of whether dentists know the product in the country is not only the problem of whether information on that product is abundant. In Japan, Gross National Product per capita (GNP) was 28,190 (current US \$, 1992) and GNI per capita was 33,660.27 In Indonesia, GNP was 670, and GNI was 720 . These results might indicate, that there is a difference in economic conditions between the countries, such as the creation of adhesives in that country; the capacity to buy the product by dentists or patients.

Answers to Q12 (Utilization of DA in the clinic) and Q14 (Application of DA for stability) indicate that Indonesian dentists tend to apply denture adhesive to patients more often than Japanese dentists do. Differences in use of denture adhesive between the two countries may be due to a difference in need of the patient, and/or in understanding the disadvantage of DA (Q3).

The use of denture adhesive is influenced by various factors. However, the methods used in this study clearly distinguished Japanese dentists from Indonesian peers. Forward selection starts without any variables in the model, whereas backward elimination starts with all of the variables. At each step in the forward selection, the variable with the smallest significance level for the score statistic, provided it is less than the chosen cutoff value, is entered into the model. All variables in the forward stepwise block that have been entered are then examined to see if they meet removal criteria. If the Wald statistic is used for deleting variables, the Wald statistics for all variables in the model are examined and the variable with the largest significance level for the Wald statistic, providing it exceeds the chosen cutoff value, is removed from the model. If no variables meet removal criteria, the next eligible variable is entered into the model. If a variable is selected for removal and it results in a model that has already been considered, variable selection stops. Otherwise, the model is estimated without the deleted variable and the variables are again examined for removal. This continues until no more variables are eligible for removal. Then, variables are again examined for entry into the model.

The process continues until either a previouslyconsidered model is encountered (which means the algorithm is cycling), or, no variables meet entry or removal criteria. In univariate analysis, there was no correlation between country and Q1 or Q2. However, statistical significance, was seen in the regression coefficient of Q1 by backward method, and that of Q2 by forward method. Other questions, which also had significant associations with countries, were significant in univariate analysis. These contradictions may happen when the sample size is not large. In such a case, input variables chosen in the logistic analysis have much influence in the result, because their interrelations affect regression coefficients. It is necessary, therefore, to conduct future research in a larger sample.

Some limitations can be identified in this study. First, indirect translation from Japanese to Indonesian might influence the results. Second, sample sizes were small. Third, there were significant differences in age between the two countries. Fourth, the school environments in this study may not be representative of other schools in the two countries due to factors such as educational setting, training program, and geographic origin. It is unknown whether the results will generalize to other samples, therefore, it is necessary to conduct future research in more diverse samples. Although caution should be exercised generalizing based on the results of this study, the variation in dentists' understanding and experiences in the clinic toward denture adhesive appeared to reflect effects of mass media, such as $\mathrm{TV}$, but not their clinical training experience. The results also suggested that it was possible to distinguish Japanese dentists from Indonesian peers with a probability of more than $95 \%$ by using the questionnaire. These methods may be useful for comparison of synthetic recognition of denture adhesive by country, and may contribute to the evaluation of denture adhesive.

A difference in dentists' understanding and experience of denture adhesive in the clinic was exhibited between Japan and Indonesia. Dentists in Japan had more information about denture adhesives. However, in the clinic, dentists in Indonesia tended to see and use denture adhesives more often than dentists in Japan.

The method used in this study clearly distinguished Japanese dentists from Indonesian peers, and is available to compare differences in recognition about denture adhesive by country. 


\section{ACKNOWLEDGEMENT}

This research was supported in part by a Grant-in-Aid (No. 14406027) for Scientific Research from the Ministry of Education, Culture, Sports, Science, and Technology, Japan.

\section{REFERENCES}

1. Tarbet W, Boone M, Schmidt NF. Effect of a denture adhesive on complete denture dislodgement during mastication. J Prosthet Dent 1980; 44: 374-8.

2. Chew CL, Boone ME, Swartz ML, Phillips RW. Denture adhesives: their effects on denture retention and stability. J Dent 1985; 13: 152-9.

3. Adisman IK. The use of denture adhesives as an aid to denture treatment. J Prosthet Dent 1989; 62: 711-715.

4. Chew CL. Retention of denture adhesives - an in vitro study. J Oral Rehabil 1990; 17: 425-434.

5. Coates AJ. Denture adhesives: a review. Aust Prosthodont J 1995; 9: 27-31.

6. Grasso JE. Denture adhesives: changing attitudes. J Am Dent Assoc 1996; 127: 90-6.

7. Woelfel JB, Kreider JA, Berg T. Deformed lower ridge caused by the relining of a denture by a patient. J Am Dent Assoc 1962; 64: 763-9.

8. Means CR. The home reliner materials: the significance of the problem. J Prosthet Dent 1964; 14: 1086-90.

9. Lamb DJ. Denture adhesives: a side effect. J Dent 1980; 8: 35-42.

10. Grasso JE, Rendell J, Gay T. Effect of denture adhesive on the retention and stability of maxillary dentures. J Prosthet Dent 1994; 72: 399-405.

11. Yankell SL. Overview of research and literature on denture adhesives. The Compendium of continuing education in dentistry 1984; 4 (Supplement): 518-21.

12. Accepted Dental Remedies. Chicago: Am Dent Assoc, 1935, 172-3.

13. Hamada T, Murata H, Yuuda S. et al. Denture adhesive, 1st Ed Dental Diamond; 2003. p. 78-82. (in Japanese).

14. Ozcan M, Kulak Y, Arikan A, Silahtar E. The attitude of complete denture wearers towards denture adhesives in Istanbul. J Oral Rehabil 2004; 31: 131-4.

15. Tarbet W, Grossman E. Observations of denture-supporting tissue during six months of denture adhesive wearing. J Am Dent Assoc 1980; 101: 789-91.

16. Shay K. Denture adhesives. Choosing the right powders and pastes. J Am Dent Assoc 1991; 122: 70-6.

17. Wilson MJ, McCord JF, Watts DC. Denture adhesives: an in vitro evaluation. J Dent Res 1990; 69: 970.

18. Coates AJ. Usage of denture adhesives. J Dent 2000; 28: 137-40.

19. Ellis B, Al-Nakash S, Lamb DJ. The composition and rheology of denture adhesives. J Dent 1980; 8: 109-18.

20. Love WB, Biswas S. Denture adhesives - PH and buffering capacity. J Prosthet Dent 1991; 66: 356-60.

21. Ekstrand K, Hensten-Pettersen A, Kullmann A. Denture adhesives: Cytotoxicity, microbial contamination, and formaldehyde content. J Prosthet Dent 1993; 69: 314-17.

22. William DG, Millicent G, Donald K. Microbial contamination in four commercially available denture adhesives. J Prosthet Dent 1994; 71: 154-8.

23. Koppang R, Berg E, Dahm S, Flöystrand F. A method for testing denture adhesives. J Prosthet Dent 1995; 73: 486-91.

24. Kelsey CC, Lang BR, Wang RF. Examining patient's responses about the effectiveness of five denture adhesive pastes. J Am Dent Assoc 1997; 128: 1532-8.

25. UNICEF. The state of the world's children 1995. Oxford University Press; 1994. p. 72-3.

26. Rogers EM, Shoemaker FF. Communication of innovation. A crosscultural approach (2nd ed.). The Free Press; 1971.

27. World Bank Group (http://devdata.worldbank.org/data-query/) 